\title{
Guest Editors’ Introduction
}

\author{
Dennis J. Downey • Charles F. Hohm
}

Published online: 1 August 2014

(C) Springer Science+Business Media New York 2014

\section{Considering Regional Sociological Associations}

The context of higher education is in a period of transition filled with change and uncertainty. It is at such times that professional associations are crucial resources in helping members to successfully navigate that change, both individually and collectively. The American Sociological Association is the primary professional association for our discipline in terms of its ability to serve as a venue for internal discussions and as a voice for external advocacy. But it is not the sole representative of the discipline. The ASA website includes a list of "Aligned Scholarly Associations" where it posts links to multiple organizations within each of the following categories: Regional Sociological Associations (9 links); State Associations (16); Aligned Associations (22); International Associations (12); Social Science Associations/Interdisciplinary Associations (31); and Commissions (1). That is an important starting point for understanding the landscape of professional associations in our discipline, and for contextualizing the position of Regional Sociological Associations (RSAs)-which is our focus here.

What is the role of RSAs? Whom do/should they serve? How should they organize themselves to do so? Those are the central questions that we explore in this issue of The American Sociologist. We do so by presenting an extended case study of one RSA: the Pacific Sociological Association (PSA). The concept of the issue originated with multiple conversations between the guest editors as they engaged in core leadership tasks for the PSA. ${ }^{1}$ They contacted Larry Nichols (editor of The American Sociologist) in response to a call for papers with research on regional associations. The ensuing discussions led to a decision to focus a full issue on the PSA.

\footnotetext{
${ }^{1}$ At the time, Hohm was Executive Director of the PSA; Downey was Program Chair for the 2013 meetings and Chair of the Publications Committee.

D. J. Downey $(\bowtie)$

California State University, Channel Islands, Camarillo, CA, USA

e-mail: dennis.downey@csuci.edu

C. F. Hohm

Department of Sociology, San Diego State University, San Diego, CA, USA

e-mail: chohm@mail.sdsu.edu
} 
In recent decades, RSAs have faced a series of challenges to their traditional role and purpose. In the era prior to easy transcontinental travel, regionals were essential to those seeking to remain professionally networked; now, with routine transcontinental flights (and instant electronic communication) the need for regional associations is no longer geographically determined. Moreover, decisions about RSA membership and meeting attendance are now made from a much larger menu of options, including not only the ASA but a variety of focused interdisciplinary associations (the Population Association of America, the National Association of Ethnic Studies, the Rural Sociological Society, etc.). Questions about the purpose and identity of RSAs are naturally made in reference to the ASA-positively or negatively. Should RSAs seek to be a "mini-ASA"? An "antiASA"? Or something else altogether? There are no easy answers, and contemporary RSAs vary widely-but they all have a strategic role to play in our profession.

RSAs have been on the frontlines of responses to changes in the profession. Most notably, RSAs have been more accommodating to those who fit into the expanding category of faculty for whom research plays a relatively smaller role in their professional responsibilities. As Keith (2004) has argued, that category represents a natural constituency for the RSAs. RSAs are more likely to draw in those less externally visible in the profession, but who collectively represent a much greater mass. RSAs also have far fewer resources, hence operate on a model much closer to a voluntary association than a professionally managed association. So, RSAs try to serve a broad swath of the profession with far fewer resources-but they collectively play a central role in the professional networks and development of many sociologists in a direct fashion-and they are consequently of crucial professional interest.

While RSAs are of crucial professional interest, the issues and themes associated with their work are not solely of professional interest-but fully sociological in their own right. All of the work of RSAs must address the challenges associated with serving a wide range of stakeholders within a highly stratified institution, identifying and prioritizing their different (and, to some extent, competing) interests, and finding ways to best organize to serve them. We hope, then, that this issue will be of interest to those far beyond PSA members-to those interested in RSAs generally, to those interested in the structure of our discipline, to those interested in professional service and stratification, among many other themes. Amy Wharton's analytical epilogue to this issue is an insightful summation that makes many of those connections clear.

\section{The Pacific Sociological Association}

What is it about the PSA which merits special attention, and which promises something useful for understanding the role of RSAs in our discipline? One obvious answer might be that it is the oldest of the regional associations, having been organized in 1929. More importantly, it is one of the largest and most vibrant of the regional associations; that is indeed one of our motivating rationales. The most compelling reason, however, is that the PSA has in the past several years been forced to confront many of the basic challenges associated with RSAs. The perspectives of PSA leaders on those challenges and the solutions with which they have been met offer a wealth of insight for and about RSAs. Here we will provide some basic background to the contemporary era of transition that is crucial to understanding the research and perspectives offered by 
contributors. The history presented below is addressed in more detail in the historical article by Dean Dorn in this issue (see also Dorn 2005 for a more extensive treatment of PSA history).

In the early 1990s, the PSA directly confronted the question of the relevance of RSAs. The PSA was then of a modest size, and it played a role quite similar to that its founders envisioned more than a half-century before-i.e., a venue for sharing research among sociologists residing in the Pacific region. But the dynamics noted above (ease of travel, and the growth of focused research associations) had eroded membership-and its traditional raison d'etre.

The revitalization of the organization began when Dean Dorn took on the executive leadership in the early 1990s. The lore that Dean tells (although too professional to put it in print) was a meeting with the incoming president of the PSA, Francesca Cancian (UC Irvine). Recognizing concerns that the association had become somewhat staid, Francesca suggested to Dean that they work with a somewhat different model for the meetings in the following year. According to Dean, Franscesca suggested: "Let's make it a big party." That was the seed of a new strategic vision through which the PSA would revitalize its social role and reorient its culture. The new culture would be characterized by greater inclusion and openness, and would prioritize collegiality over status-and the cultural reorientation would ultimately have much broader implications.

It was propitious timing for such changes. The early 1990s was a time of great introspection in higher education about its mission and priorities. The publication of Ernest Boyer's influential Scholarship Reconsidered: Priorities of the Professorate in 1990 was both an impetus to and an embodiment of those shifts. As Boyer wrote: "Clearly the time has come not only to reconsider the meaning of scholarship but also to take the next step and consider ways by which the faculty reward system can be improved" (p. 35). He was mostly addressing the faculty reward system within the structure of the university-but the sentiment clearly had implications for professional associations as well, as the landscape of the profession was changing.

With the democratization of higher education in full swing, a wider range of colleges and universities was proliferating-including faculty with a wider range of expectations and challenges, many trained as research sociologists but whose work was overwhelmingly focused on teaching. That generated demand for a more inclusive association that addressed the breadth of the needs and interests of those faculty members-including the growing ranks of temporary (or permanent) adjuncts. Dean was in a strategic position to see those changes because he was at the forefront of the movement within the discipline promoting the scholarship of teaching and learning (SoTL), and had just begun his tenure as editor of Teaching Sociology. (Peter Collier's essay in this volume is a testimony to the role of SoTL in the PSA.)

The job market for new PhDs was also becoming more competitive, with increased expectations of professional activities, presentations, and publications. (See Jonathan Turner's essay regarding the impact of that shift.) As graduate students sought increased professional credentials, the PSA welcomed them. They found rich developmental experiences presenting their work, networking with faculty in a collegial atmosphere, and even organizing their own conference sessions. Undergraduates too, began to seek out opportunities for conference presentations, as undergraduate research was being institutionalized in higher education (especially in private liberal arts colleges). The evolution of the undergraduate component of the PSA program was 
eventually led by Virginia Mulle, who shaped that component over multiple iterations into a central part of the program. (See Mulle 2012, as well as the essay by Vik Gumbhir in this issue). All of these shifts led to a relatively dramatic reconfiguration of the PSA-its membership, its goals, its vision of itself, its meetings.

After two decades with Dean at the helm, the PSA could regularly expect 1,100 or 1,200 attendees at its meetings, which had a reputation for vibrancy and collegiality. One telling symbol of the attachment that members have to the PSA is that many faculty members who participated in the PSA while in graduate school, and who subsequently found work outside of the Pacific region, continue to make the spring trip back to the meetings. (Lora Vess explains that phenomenon in her essay.)

It is crucial to underscore that Dean Dorn played a singular role in the revitalization of the PSA: he provided the executive leadership, the heart and soul, and the boundless energy to make it happen. PSA members and leaders relied on him to plan and run the annual meetings, manage internal and external communication, and oversee all governance processes. He also managed all financial issues, and kept the association in increasingly positive financial health. As executive leader, he refused payment-even after he formally became the Executive Director (which mostly was official nod to what had been the previous situation). As virtually any voluntary association attests, leadership is a constant challenge, since resources (financial and time) are always in short supply. In short, Dean was a one-person solution to the myriad challenges confronted by voluntary associations.

The "Dean Dorn era" in the PSA came to a close in 2010, when he stepped down as Executive Director. Dean is still very involved in guiding the association (formally as Treasurer, and informally as sage counselor to new cohorts of leaders), but the era characterized by his singular leadership is over. Dean's departure has required the PSA to confront anew the classic challenges of voluntary associations-most specifically, how to organize ourselves in the best way with scarce resources to serve our members. Kathy Kuipers and Laura Obernesser's article lays out some of the central challenges of governance in that context. Jane Prather's essay explains how a more inclusive model for the PSA succeeded in expanding membership even as it increased the challenges of self-governance.

Equally important in shaping the current context is that the PSA has seen a gradual but cumulatively dramatic shift in membership composition over the past two decades. While the PSA had been extremely successful in bringing in students, the association reached a tipping point in the mid/late 2000s: the association-and its meetings-now regularly include more students than faculty. Moreover, the faculty themselves are much more likely to be employed in comprehensive universities than research universities. Patricia Gwartney's article provides a thorough and insightful analysis of the changing membership composition and its implications. The increasing breadth of membership raises tremendous challenges to serving all of them-and the PSA has gone to great lengths to find out how to respond. Keith Farrington's article reports on a focused member survey of faculty in doctoral-granting programs in the region to learn about their perceptions and participation in the PSA. Todd Migliaccio and Jennifer Murphy's article assesses how successful the PSA has been in serving the central (and somewhat amorphous) category of teacher-scholars. And Linda Rillorta offers an essay on how the PSA has served community college faculty. Each of those contributions provides wonderful insights about the challenges of serving an increasingly diverse membership. 
The most visible aspect of associational structures in which the challenges and conflicts of serving a broad membership are manifest is in the structure of the annual meetings. In the 1990s, broadening the balance of members and presentations enriched the association, but two decades later the PSA was suffering from a perception that it was no longer an appropriate venue for presenting discipline-leading research. Members routinely complained about the "unevenness" of presentations, and sessions that did little to engage their sociological imaginations or set appropriate professional expectations. That has led to ongoing efforts to revise the structure of the meetingsmost specifically the options for presentation formats, and the processes by which the meetings are organized. Two articles analyze those efforts and their outcomes. Enrico Marcelli and his colleagues take a longitudinal perspective in assessing shifts in recent years. Downey and Amy Orr focus their attention on specific changes that were implemented in 2013, and modified in 2014. Several essays provide more focused perspectives on how those changes were received. Matt Carlson and Tina Burdsall focus on the specific issue of research-in-progress sessions; Liahna Gordon points to what might have been lost; and Harry Mersmann provides a rich metaphor in his essay which puts the issue of "unevenness" in a very different light.

The issue of diversity in membership does not simply refer to the faculty status and affiliations; it also refers to the welcoming of traditionally underrepresented groups into the discipline. The PSA has a formal commitment to underrepresented members of our profession; how does that formal commitment translate to the ability to effectively serve members? Michelle Madsen Camacho, Sarita Gaytán and Greg Pietro raise that question, focusing in part on trends in presentations associated with race and ethnicity at the meetings. Two essays focus on specific aspects of the PSA's service to underrepresented groups: Arduizir Carli Richie-Zavaleta and LaTasha Wormsley discuss their involvement in mentoring programs to support underrepresented faculty; Ramon Torrecilha assesses the PSA's opportunities and limitations to promoting diversity in the discipline based on its participation in national programs with which he was closely involved.

One of the issues that brings us full circle with RSAs is the question of regionality in a context where geography is becoming markedly less relevant. That issue comes up in a most interesting manner with the journal. Is an RSA journal truly "regional" in any meaningful sense? Does (or should) Sociological Perspectives play a regional role? The current editorial team (Bob O'Brien, James Elliott, and Jessica Schultz) present an interesting analysis of long-term trends in the regionality of the journal in relation to other characteristics. Dave Smith's following essay brings up regionality as one among many challenges in the "brave new world" of academic publishing. And the journal is not the only area where the question of regionality asserts itself. Earl Babbie's essay discusses the role of the PSA in the broader Pacific region (far beyond the Western United States), and Ed Nelson discusses the California Sociological Association and its mission vis-à-vis the PSA given its more focused but overlapping geographical boundaries.

\section{Organization}

We have organized the issue in two parts. The first part addresses "changing roles and contexts"; the second focuses on "changing membership and constituencies." Of 
course, that division is somewhat artificial, as all of the challenges addressed-selfgovernance, meeting formats, membership composition, editorial direction, etc.-are mutually entwined, and fundamental to the health and future of RSAs. Throughout, we will be brought back again and again to variations on the themes presented at the beginning of this introduction: What is the role of the PSA? Whom does-and should-it serve? How can we best organize ourselves to do so? Those are challenging issues-but if any group of professionals is up to the task of identifying solutions, it should be sociologists.

Contributions to the issue are of two types: articles and essays. Articles present empirical research on their topic; essays present shorter and more personal perspectives. Each type of contribution complements the other, and both are essential to a fuller understanding of our subject matter. Across the collection as a whole, you will see many different answers to the questions identified above, but it is clear that all come from a deep sense of attachment to and affection for the PSA. We should add: essays are interspersed with articles in ways that make obvious connections between them, but they are in no way direct debates or responses on a theme. Contributors did not read over others' manuscripts, and in any event the topics recommended to authors invited to submit were only loosely defined.

Acknowledgments We would like to acknowledge and thank two important individuals who have been essential in bringing this issue to reality. First, Larry Nichols, editor of The American Sociologist, has been supportive and helpful from the time that we brought the idea to him-which was a response to his own call for a special issue on RSAs. We thank him for supporting our extended vision for an issue on the PSA-and for diligently carrying out all of the crucial tasks - small and large - that are essential to a collection such as this.

Second, we would like to acknowledge and thank Dean Dorn. Without Dean, this issue would never have been undertaken-because, in all likelihood, the PSA would not be worthy of such extensive consideration. All of us in the Pacific Region owe Dean a tremendous debt of gratitude for what he has done over the past quarter century to enliven our profession and careers. For some, that debt is more direct than others. Our work on this issue is a tribute to Dean in the best way that we know how: To contribute to the ongoing vibrancy of the association that he (re)built for all of us. Our hope is that that this collection serves to assist the PSA-and other regional professional associations-to think strategically about their goals and how to achieve them. And, in the process, we hope that it prompts us to consider more deeply the broader goals of our discipline.

\section{References}

Boyer, E. L. (1990). Scholarship reconsidered: Priorities of the professorate. San Francisco: Jossey-Bass.

Dorn, D. S. (2005). Seventy-five years of the pacific sociological association, 1929-2004. Sacramento: Pacific Sociological Association.

Keith, B. (2004). Disciplinary culture and organizational dissonance: the regional association in american sociology. Sociological Focus, 37(2), 83-105.

Mulle, V. (2012). The undergraduate experience of the PSA. The Pacific Sociologist, $20(2), 9$. 